This item was submitted to Loughborough's Research Repository by the author.

Items in Figshare are protected by copyright, with all rights reserved, unless otherwise indicated.

\title{
Experimental assessment of mixed-mode partition theories for generally laminated composite beams
}

PLEASE CITE THE PUBLISHED VERSION

http://dx.doi.org/10.1016/j.compstruct.2014.12.064

PUBLISHER

(C) Elsevier

VERSION

AM (Accepted Manuscript)

\section{PUBLISHER STATEMENT}

This work is made available according to the conditions of the Creative Commons Attribution-NonCommercialNoDerivatives 4.0 International (CC BY-NC-ND 4.0) licence. Full details of this licence are available at: https://creativecommons.org/licenses/by-nc-nd/4.0/

\section{LICENCE}

CC BY-NC-ND 4.0

\section{REPOSITORY RECORD}

Harvey, Christopher M., Matthew R. Eplett, and Simon Wang. 2015. "Experimental Assessment of Mixedmode Partition Theories for Generally Laminated Composite Beams". figshare. https://hdl.handle.net/2134/16596. 


\title{
Experimental assessment of mixed-mode partition theories for generally laminated composite beams
}

\author{
C. M. Harvey, M. R. Eplett and S. Wang* \\ Department of Aeronautical and Automotive Engineering, Loughborough University, Loughborough, \\ Leicestershire LE11 3TU, UK
}

\begin{abstract}
Three different approaches to partitioning mixed-mode delaminations are assessed for their ability to predict the interfacial fracture toughness of generally laminated composite beams. This is by using published data from some thorough and comprehensive experimental tests carried out by independent researchers (Davidson et al., 2000 and 2006). Wang and Harvey’s (2012) Euler beam partition theory is found to give very accurate prediction of interfacial fracture toughness for arbitrary layups, thickness ratios and loading conditions. Davidson et al.'s (2000) nonsingular-field partition theory has excellent agreement with Wang and Harvey’s Euler beam partition theory for unidirectional layups. Although Davidson et al.'s partition theory predicts the interfacial fracture toughness of multidirectional layups reasonably well, overall Wang and Harvey's Euler beam partition theory is found to give better predictions. In general, the singularfield approach based on 2D elasticity and the finite element method gives poor predictions of fracture toughness.
\end{abstract}

Keywords: Composite materials, Delamination, Fracture toughness, Mixed-mode tests, Mixedmode partition

\footnotetext{
* Corresponding Author

Email addresses: s .wang@lbor . ac .uk (S. Wang), c . m . harvey@lboro . ac . uk (C. M. Harvey),

m.r.eplett@lboro.ac.uk (M. R. Eplett)
} 


\begin{tabular}{|c|c|}
\hline \multicolumn{2}{|c|}{ NOMENCLATURE } \\
\hline$A_{1}, A_{2}, A$ & extensional stiffness of upper, lower and intact beams \\
\hline$B_{1}, B_{2}, B$ & coupling stiffness of upper, lower and intact beams \\
\hline$D_{1}, D_{2}, D$ & bending stiffness of upper, lower and intact beams \\
\hline E & Young’s modulus \\
\hline$E_{1 \mathrm{f}}$ & flexural modulus \\
\hline$G_{I}, G_{I I}, G$ & mode I, mode II and total energy release rate \\
\hline$G_{I c}, G_{I I c}, G_{c}$ & mode I, mode II and total fracture toughness \\
\hline$h_{1}, h_{2}, h$ & thicknesses of upper, lower and intact arms \\
\hline$M_{1}, M_{2}$ & bending moments on upper and lower arms \\
\hline$M_{1 B}, M_{2 B}$ & bending moments at crack tip on upper and lower arms \\
\hline$M_{c}, N_{c}$ & concentrated crack tip moment and force \\
\hline$n_{1}, n_{2}$ & numbers of plies in the upper and lower arms \\
\hline$N_{1}, N_{2}$ & axial forces on upper and lower arms \\
\hline$N_{1 B}, N_{2 B}$ & axial forces at crack tip on upper and lower arms \\
\hline$\beta, \beta^{\prime}$ & pure mode II relationships from the first and second set \\
\hline$\gamma$ & thickness ratio $h_{2} / h_{1}$ \\
\hline$\theta, \theta^{\prime}$ & pure mode I relationships from the first and second set \\
\hline$\mu$ & shear modulus \\
\hline$v$ & Poisson’s ratio \\
\hline$\sigma$ & standard deviation \\
\hline$\Omega$ & mode mix parameter \\
\hline \multicolumn{2}{|l|}{ Abbreviations } \\
\hline CUD & constrained unidirectional \\
\hline DCB & double cantilever beam \\
\hline ENF & end-notched flexure \\
\hline ERR & energy release rate \\
\hline MMB & mixed-mode bending \\
\hline MD & multidirectional \\
\hline SSLB & symmetric single leg bending \\
\hline UD & unidirectional \\
\hline UENF & unsymmetric end-notched flexure \\
\hline USLB & unsymmetric single leg bending \\
\hline
\end{tabular}




\section{Introduction}

Delamination is a major concern in the application of laminated composite materials and has attracted the attention of many researchers for decades. Although delamination generally occurs as mixed-mode fracture with all three opening, shearing and tearing actions (i.e. mode I, II and III), 1D delamination has received more attention as it is simpler, still captures the essential mechanics, and also serves as a stepping stone towards the study of general mixed-mode delamination. The expression '1D delamination' means that a delamination propagates in one direction with mode I and mode II action only. Examples of 1D delamination include throughwidth delamination in double cantilever beams (DCBs), and blisters in laminated composite plates and shells. A central task in studying $1 \mathrm{D}$ delamination is to partition the total energy release rate (ERR) $G$ of a mixed-mode fracture into its individual mode I and II ERR components, that is, $G_{I}$ and $G_{I I}$, which govern the propagation of the mixed-mode fracture.

Several relatively well-known partition theories for beam structures are Williams' partition theory [1], Suo and Hutchinson's partition theory [2,3], Davidson et al.'s partition theories [4-6] and Wang and Harvey's partition theories [8-12]. All these theories assume a rigid crack interface, that is, they assume that no relative crack tip separation occurs before crack growth. Therefore these theories effectively consider brittle fracture. It is worth noting that the assumption of a rigid crack interface has profound mechanical implications on mixed-mode partitioning. Some further points regarding this will be given later. Williams’ partition theory [1] is based on Euler beam theory, and for rigid interfaces is applicable to midplane delamination in laminated unidirectional (UD) composite beams only. It is often called the 'global partition theory'. Suo and Hutchinson's partition theory [2,3] is based on 2D-elasticity theory and stress intensity factors and is applicable to both midplane delamination and offset delamination (i.e. not on the midplane) in laminated UD composite beams. It is often called the 'local partition theory'. Davidson et al.'s partition theories [4-6] include a singular-field partition theory and a non- 
singular-field partition theory. Both theories are derived by using a combined analytical and numerical approach based on 2D elasticity with stress intensity factors. Experimental data are also used in the derivation of the non-singular-field partition theory [4-6]. Both are applicable to delamination in laminated composite beams with arbitrary through-thickness location and with arbitrary layup. Wang and Harvey’s partition theories [8-12] include an Euler beam partition theory, a Timoshenko beam partition theory, and a partition theory for 2D elasticity. These theories are completely analytical and derived by discovering a fundamentally different and powerful methodology. Stress intensity factors are not used. All of them are applicable to delamination in laminated composite beams with arbitrary through-thickness location and with arbitrary layup.

Which of the above partition theories [1-12] can best complete the central task: to partition the total ERR $G$ into $G_{I}$ and $G_{I I}$, and in doing so, predict the fracture toughness? Only measurements from experimental tests are able to answer this question. Although there are numerous experimental investigations reported in literature, the ones in Refs. [5-7,11,13-16] may represent some of the most comprehensive and convincing ones. By using a linear failure locus (found to be a good approximation for the tested composite material), an experimental investigation for delamination in UD laminates is reported in Ref. [15] for the assessment of Williams' partition theory [1] and Suo and Hutchinson's 2D-elasticity partition theory [2,3]. The conclusion of those researchers was that the former agrees with the linear failure locus much better than the latter does. The experimental investigations reported in Refs. [5-7] are for both UD and multidirectional (MD) laminates. No specific failure locus is assumed, and instead a failure locus is experimentally determined in terms of the total critical ERR $G_{c}$ and $G_{I I} / G$ by using the test data for midplane delamination in UD laminates. All the partition theories agree on this particular case and so the failure locus is reliably obtained. Then, the assessment of different partition theories is made against this midplane failure locus for delamination at various through- 
thickness locations and with various layups. The experimental investigation in Ref. [5] assesses Williams' partition theory [1] and Davidson et al.'s 2D-elasticity singular field and non-singularfield partition theories [4-6]. Quoting from Ref. [5], the conclusions are: (1) "a singular-fieldbased definition of mode mix will not produce accurate delamination growth predictions for certain composite materials and loadings"; (2) "an alternative definition of mode mix, originally developed by Williams and successfully applied to other composite systems [14-16], is not universally applicable"; (3) the non-singular-field partition theory "would appear to be more appropriate than the classical approach for many current continuous fibre composites.” Even more comprehensive experimental assessments are given in Refs. [6,7] for Davidson et al.'s 2Delasticity singular-field partition theory and non-singular-field partition theory [4-6], including results from various finite element simulations. A large number of UD and MD laminates are tested in different bending and tension configurations. The assessment methodology is the same as that in the study [5], that is, a failure locus is experimentally determined in terms of the total critical ERR $G_{c}$ and $G_{I I} / G$ by testing UD laminates with midplane delamination. Different partition theories are then assessed against this failure locus using test specimens with delamination at various through-thickness locations and with various layups. The assessment concluded that Davidson et al.’s 2D-elasticity non-singular-field partition theory [4-6] provides highly accurate delamination growth predictions for a variety of laminate layups and loadings. Conversely, the 2D-elasticity singular-field partition theory [4-6] is shown to have relatively poor accuracy.

Recently, the authors have made a detailed experimental assessment [11] of Williams' [1], Suo and Hutchinson's [2,3], and Wang and Harvey's [8-11] partition theories using the same methodology and test data as that used in the study in Ref. [15]. It was shown that the predictions from Wang and Harvey's Euler beam partition theory [8-11] have the best agreement with the linear failure locus that was originally suggested in Ref. [15] for the composite material in 
question, following it extremely closely. The predictions from Wang and Harvey's partition theories for Timoshenko beams and for 2D elasticity, and from Suo and Hutchinson's 2Delasticity partition theory, are far away from the failure locus, and Williams’ partition theory [1] performs much better than them. The very latest work [17] on the topic is also highly regarded. The same assessment methodology to that used in Refs. [5-7] is used (see above). It is shown that Wang and Harvey’s Euler beam partition theory [8-11] and Davidson et al.’s non-singular-field partition theory [4-6] have similar performance. Although the authors conclude that none of the current analytical partition theories "are able to predict failure in asymmetric composite laminates”, the data presented in the paper shows that both Davidson et al.'s non-singular-field partition theory [4-6] and Wang and Harvey's Euler beam partition theory [8-11] actually show quite reasonable agreement with the midplane failure locus.

In conclusion, from these four independent assessments it appears that both Wang and Harvey's Euler beam partition theory [8-11] and Davidson et al.'s non-singular-field partition theories [4-6] provide the best ERR partitions, $G_{I}$ and $G_{I I}$, which govern the growth of delamination. These two partition theories, however, are derived from very different approaches. The former is based on Euler beam theory and is derived completely analytically, while the latter is based on 2D-elasticity theory and is derived by using a combined analytical, numerical and experimental approach. A detailed explanation is given in Ref. [11] for why Wang and Harvey's Euler beam partition theory [8-11] agrees so well with the test data and for why it must correctly capture the underlying mechanics. To summarise the explanation in Ref. [11], it appears that the brittle nature of delamination growth on a rigid interface is governed by global ERR partitions. 'Global partitions' are those calculated over the whole length of the interface that is mechanically affected by the crack tip [8-11]. Note that 'global' in this context has a different meaning to when it is used to describe Williams' partition theory [1], which as explained above, is often described as global. Using global ERR partitions, both Wang and Harvey's Timoshenko beam and 2D- 
elasticity partition theories converge to Wang and Harvey's Euler beam partition theory [8-11]. The same is true for partitions obtained globally from finite element method simulations [11]. Williams' partition theory [1] is in fact a partially-global partition theory (this will be explained later). This explains why it performs much better in the assessment in Ref. [11] than the other partition theories except for Wang and Harvey's Euler beam partition theory [8-11]. Now, it is reasonable to speculate that Davidson et al.'s 2D-elasticity non-singular-field partition theory [46] approaches to Wang and Harvey's Euler beam partition theory [8-11] by introducing the mode mix parameter $\Omega$ which is obtained with the aid of experimental data. The present work aims to assess these two theories thoroughly using the experimental data in Refs. [6,7] and to explore their connections.

The structure of the paper is as follows. The two partition theories are briefly given in Section 2. In Section 3, data from the experimental tests described in Refs [6,7] is analysed using the two partition theories. Finally, conclusions are given in Section 4.

\section{Mixed-mode partition theories}

\subsection{Wang and Harvey's Euler beam partition theory [8-11]}

Wang and Harvey's partition theories are for 1D fractures in straight beams and axisymmetric plates made of either isotropic or laminated composite materials. Full details of the theories are given in Refs. [8-11]. Only a brief introduction is given in this paper for a laminated composite DCB as shown in Fig. 1a with its associated geometry and DCB tip bending moments and axial forces. Fig. 1b shows the two bending moments and two axial forces at the crack tip at location B. The total ERR $G$ is calculated as follows $[8,10]$ :

$$
\begin{gathered}
G=\frac{1}{2 b^{2}}\left[\frac{M_{1 B}^{2}}{D_{1}^{*}}+\frac{M_{2 B}^{2}}{D_{2}^{*}}-\frac{M_{B}^{2}}{D^{*}}+\frac{N_{1 B}^{2}}{A_{1}^{*}}+\frac{N_{2 B}^{2}}{A_{2}^{*}}-\frac{N_{B}^{2}}{A^{*}}-\frac{2 B_{1} M_{1 B} N_{1 B}}{B_{1}^{*}}-\frac{2 B_{2} M_{2 B} N_{2 B}}{B_{2}^{*}}+\frac{2 B M_{B} N_{B}}{B^{*}}\right] \\
=\frac{1}{2 b^{2}}\left\{\begin{array}{llll}
M_{1 B} & M_{2 B} & N_{1 B} & N_{2 B}
\end{array}\right\}[C]\left\{\begin{array}{llll}
M_{1 B} & M_{2 B} & N_{1 B} & N_{2 B}
\end{array}\right\}^{T} \\
N_{B}=N_{1 B}+N_{2 B} \quad, \quad M_{B}=M_{1 B}+M_{2 B}+\left(h_{1} N_{2 B}-h_{2} N_{1 B}\right) / 2
\end{gathered}
$$




$$
A_{i}^{*}=A_{i}-B_{i}^{2} / D_{i} \quad, \quad B_{i}^{*}=B_{i}^{2}-A_{i} D_{i} \quad, \quad D_{i}^{*}=D_{i}-B_{i}^{2} / A_{i}
$$

The total ERR $G$ is of quadratic form in terms of the crack tip moments and forces $M_{1 B}$, $M_{2 B}, N_{1 B}$ and $N_{2 B}$. The coefficient matrix [C] is given in full in Appendix A. The extensional, coupling and bending stiffnesses are denoted by $A, B$ and $D$ respectively. The range of $i$ is 1 2, which refers to the upper and lower arms respectively. No subscript is used for the intact part of the laminate. $A_{1}$ is therefore the extensional stiffness of the upper beam and $A$ is the extensional stiffness of the intact part of the laminate, etc. Note that these quantities take different values under the plane-strain assumption from those under the plane-stress assumption; however, there is no difference between the two assumptions in the following development.

According to Wang and Harvey's Euler beam partition theory [11], the mode I and II components of the total ERR $G$, denoted by $G_{I E}$ and $G_{I I E}$ respectively, are

$$
\begin{aligned}
G_{I E} & =C_{I E}\left(M_{1 B}-\frac{M_{2 B}}{\beta_{1}}-\frac{N_{1 B}}{\beta_{2}}-\frac{N_{2 B}}{\beta_{3}}\right)\left(M_{1 B}-\frac{M_{2 B}}{\beta_{1}^{\prime}}-\frac{N_{1 B}}{\beta_{2}^{\prime}}-\frac{N_{2 B}}{\beta_{3}^{\prime}}\right) \\
G_{I I E} & =C_{I I E}\left(M_{1 B}-\frac{M_{2 B}}{\theta_{1}}-\frac{N_{1 B}}{\theta_{2}}-\frac{N_{2 B}}{\theta_{3}}\right)\left(M_{1 B}-\frac{M_{2 B}}{\theta_{1}^{\prime}}-\frac{N_{1 B}}{\theta_{2}^{\prime}}-\frac{N_{2 B}}{\theta_{3}^{\prime}}\right)
\end{aligned}
$$

where $c_{I E}$ and $c_{I I E}$ are two constants, and $\left(\theta_{i}, \beta_{i}\right)$ and $\left(\theta_{i}^{\prime}, \beta_{i}^{\prime}\right)$ represent the two sets of orthogonal pure modes where the range of $i$ is from 1 to 3 . For example, when $M_{2 B}=\theta_{1} M_{1 B}$ and $N_{1 B}=N_{2 B}=0$, pure mode I occurs because the relative shearing displacement just behind the crack tip is zero. This pure-mode-I mode is denoted by $\theta_{1}$. Its orthogonal pure-mode-II mode is $\beta_{1}$, which corresponds to zero crack tip opening force. Here, the mathematical meaning of 'orthogonal' is

$$
\left\{\begin{array}{llll}
1 & \theta_{1} & 0 & 0
\end{array}\right\}[C]\left\{\begin{array}{llll}
1 & \beta_{1} & 0 & 0
\end{array}\right\}^{T}=0
$$

For simplicity, Eq. (6) can be written as $\theta_{1}=\operatorname{orthogonal}\left(\beta_{1}\right)$. Similarly, when $M_{2 B}=\theta_{1}^{\prime} M_{1 B}$ and $N_{1 B}=N_{2 B}=0$, pure mode I occurs because the crack tip shearing force is zero. This puremode-I mode is denoted by $\theta_{1}^{\prime}$. Its orthogonal pure-mode-II mode is $\beta_{1}^{\prime}$, which corresponds to 
zero crack tip opening displacement. An important feature of the pure modes from Euler beam theory is that the two sets of pure modes do not necessarily coincide. For example, the $\theta_{1}$ puremode-I mode corresponds to zero relative shearing displacement but with non-zero crack tip shearing stress. Also, the $\beta_{1}$ pure-mode-II mode corresponds to zero opening crack tip stress but with non-zero crack tip relative opening displacement. These characteristics arise from the rigidity of the interfaces and result in 'stealthy interaction' [8-11] between the $\theta_{i}$ pure-mode-I modes and the $\beta_{i}$ pure-mode-II modes. Eq. (6) shows that the interaction between the $\theta_{1}$ puremode-I mode and the $\beta_{1}$ pure-mode-II mode produces zero net ERR due to their orthogonality; however, this does not mean there is no interaction between them. In fact, interactions do exist between them as shown by Eqs. (4) and (5). The crack tip opening stress in the $\theta_{i}$ pure-mode-I mode does work on the non-zero opening displacement in the $\beta_{i}$ pure-mode-II mode while the non-zero crack tip shearing stress in the $\theta_{i}$ pure-mode-I mode does work on the shearing displacement in the $\beta_{i}$ pure-mode-II mode. These interactions change the mode I and II ERR partitions and are called 'stealthy interaction' in Refs. [8-11] because they produce zero net ERR and their action is not immediately obvious.

In Timoshenko beam theory the two sets of pure modes coincide on the first set resulting in no stealthy interaction. It is worth noting that when ERR is calculated using the whole length of the interface that is mechanically affected by the crack tip, numerical simulations show that Euler beam, Timoshenko beam and 2D elasticity partitions are the same as that of Euler beam partitions in Eqs. (4) and (5), hence, the Euler beam partitions are also called global partitions.

It is important to note that the orthogonal property demonstrated in Eq. (6) exists between any pair of pure modes in the first set of pure modes $\left(\theta_{i}, \beta_{i}\right)$, that is, $\theta_{i}=\operatorname{orthogonal}\left(\beta_{\mathrm{i}}\right)$. This property also applies to any pair of pure modes in the second set of pure modes $\left(\theta_{i}^{\prime}, \beta_{i}^{\prime}\right)$, that is, $\theta_{i}^{\prime}=\operatorname{orthogonal}\left(\beta_{\mathrm{i}}^{\prime}\right)$. Therefore, as long as one pure mode from each set, say $\theta_{1}$ in the first set 
and $\theta_{1}^{\prime}$ in the second set, is found then the others can be determined by using orthogonal condition in Eq. (6). The details of $c_{I E}, c_{I I E},\left(\theta_{i}, \beta_{i}\right)$ and $\left(\theta_{i}^{\prime}, \beta_{i}^{\prime}\right)$ are given in Appendix B. It is also worth noting that the two sets of pure modes $\left(\theta_{i}, \beta_{i}\right)$ and $\left(\theta_{i}^{\prime}, \beta_{i}^{\prime}\right)$ coincide at the first set for non-rigid interfaces, even in Euler beam theory [18].

Eqs. (4) and (5) are easily reduced for isotropic materials. A thickness ratio $\gamma=h_{2} / h_{1}$ is now introduced. The partitions become

$$
\begin{gathered}
G_{I E}=C_{I E}\left(M_{1 B}-\frac{M_{2 B}}{\beta_{1}}-\frac{N_{1 B e}}{\beta_{2}}\right)\left(M_{1 B}-\frac{M_{2 B}}{\beta_{1}^{\prime}}\right) \\
G_{I I E}=C_{I I E}\left(M_{1 B}-\frac{M_{2 B}}{\theta_{1}}-\frac{N_{1 B e}}{\theta_{2}}\right)\left(M_{1 B}-\frac{M_{2 B}}{\theta_{1}^{\prime}}-\frac{N_{1 B e}}{\theta_{2}^{\prime}}\right)
\end{gathered}
$$

where

$$
N_{1 B e}=N_{1 B}-N_{2 B} / \gamma
$$

The details of $c_{I E}, c_{I I E},\left(\theta_{i}, \beta_{i}\right)$ and $\left(\theta_{i}^{\prime}, \beta_{i}^{\prime}\right)$ are given in Appendix C. Williams' partition theory [1] only uses the $\left(\theta_{1}^{\prime}, \beta_{1}^{\prime}\right)$ pure-mode pair in Eqs. (7) and (8) to partition a mixed-mode crack in a DCB with bending moments at the crack tip $M_{1 B}$ and $M_{2 B}$. That is why it is only applicable when $\gamma=1$ (for rigid interfaces) and why it is also a partially-global partition theory. Eqs. (4), (5), (7) and (8) give the full global partition theory.

\subsection{Davidson et al.’s 2D-elasticity non-singular-field partition theory [4-6]}

Davidson et al.’s non-singular partition theory [4-6], which is based on 2D elasticity, is given by the following formula:

$$
\frac{G_{I I}}{G}=\frac{\left[N_{c} \sqrt{c_{1}} \cos \Omega+M_{c} \sqrt{c_{2}} \sin (\Omega+\Gamma)\right]^{2}}{c_{1} N_{c}^{2}+c_{2} M_{c}^{2}+2 \sqrt{c_{1} c_{2}} N_{c} M_{c} \sin \Gamma}
$$

where $N_{c}$ and $M_{c}$ are the concentrated crack tip force and moment respectively. Details of all the quantities in Eq. (10) can be found in Refs. [4-6] and are not copied here; however, giving the details of $\Omega$, which is called the 'mode mix parameter', is worthwhile. 


$$
\Omega=\left\{\begin{array}{ccc}
-24 & & \eta<-0.468 \\
60.409 \eta-41.738 \eta^{3} & \text { if } & -0.468<\eta<0.468 \\
24 & & \eta>0.468
\end{array}\right.
$$

Note that $\eta$ in Eq. (11) is given by $\eta=\log _{10}(\gamma)$. The mode mix parameter $\Omega$ is determined with the aid of experimental data.

\section{Assessment}

As far as the authors' knowledge is concerned, the work in Refs. [5-7] represents some of the most comprehensive and thorough experimental test data available for the study of interfacial delamination toughness in generally laminated composite beams. As stated earlier in the Introduction, the present work aims to assess the relative performances of Wang and Harvey's Euler beam partition theory [8-11] and Davidson et al.'s non-singular-field partition theory [4-6] as they have been identified as the best performers in several different experimental assessment exercises [5-7,11,17]. The same format as Refs. [5-7] is followed. Three groups of test specimens are considered, namely, UD specimens, constrained unidirectional specimens (CUD) and MD specimens. Three partition approaches are compared. They are Wang and Harvey's Euler beam partition theory [8-11], Davidson et al.'s non-singular-field partition theory [4-6], and finite element method simulation based on 2D elasticity to obtain the singular-field partition. The partition results from the latter two are mostly just reproduced from the work in Refs. [6,7] with two exceptions which are noted later. The readers are referred to Refs. [6,7] for the full details. Two sets of graphite/epoxy laminates are considered. They are C12K/R6376 of low toughness and T800H/3900-2 of high toughness. The UD material properties from Refs. [6,7] are reproduced in Table 1. Note that, as in Refs. [6,7], the experimentally-determined flexural modulus $E_{1 \mathrm{f}}$ is used to calculate the laminate stiffnesses in place of the manufacturer-quoted $E_{11}$. 


\subsection{Unidirectional specimens}

UD specimens made from C12K/R6376 material with midplane and offset delaminations are considered in this sub-section. The results are shown in Table 2 and Fig. 2. Note that in Table 2, the column $M_{2} / M_{1}$ represents the bending moment ratio applied to the upper and lower arms. For the UENF specimens with Wang and Harvey’s Euler beam partition theory, contact has to be considered and this will slightly modify the actual bending moment ratio at the crack tip, and these are the additional values that are given in brackets. Details of the contact calculation can be found in Refs. [9,10].

As expected, all three partition approaches give largely identical partition results for midplane delaminations. By using these results, a failure locus is experimentally determined in terms of the total critical ERR $G_{c}$ and the partition $G_{I I} / G$ and this is shown in Fig. 2 as the solid piecewise straight line. The error bars show plus/minus one standard deviation from each data point based on Davidson et al.'s testing of at least five specimens for each test [6,7]. Up to plus/minus one standard deviation of the failure locus is also shown by the shadowed area. The different partition theories are assessed against this failure locus for offset delamination. It is seen that Wang and Harvey's Euler beam partition theory and Davidson et al.'s non-singular-field partition theory again give largely identical partition results and agree very well with the failure locus; however, the singular-field partition results are generally not in good agreement with this failure locus.

It is surprising to see the excellent-almost identical-agreement between Wang and Harvey's Euler beam partition theory and Davidson et al.’s non-singular-field partition theory, because the former is derived completely analytically, and the latter is derived with the aid of experimental work. In order to investigate this observation further, Fig. 3 shows the difference between the partitions $G_{I I} / G$ from both partition theories over a range of bending moment ratios, $M_{2 B} / M_{1 B}$, and thickness ratios, $\log _{10}(1 / \gamma)$. Within the range $1 / 3<\gamma<3$, or with reference to Eq. (11), the range $-0.468<\eta<0.468$, the two approaches are approximately 
identical, which is strong support for the theoretical basis behind Wang and Harvey's Euler beam partition theory. Cross data markers for each UD specimen test point $\left(M_{2 B} / M_{1 B}, \gamma\right)$ tested in Ref. [6] are also overlaid onto Fig. 3. It is interesting to note that every test point lies in the region where there is excellent agreement between the two partition theories. This begs the question, outside of the region $1 / 3<\gamma<3$, which theory is better? Although this is not conclusive, the data presented in Ref. [17] shows that Wang and Harvey’s Euler beam partition theory agrees well with the experimental measurements when $\gamma<1 / 3$ and much better than Davidson et al.’s non-singular-field partition theory.

\subsection{Constrained unidirectional specimens}

CUD specimens made from C12K/R6376 material are considered in this sub-section with midplane and offset delaminations. The specimen layups are given at the bottom of Table 3 and the partition results are shown in Table 3 and Fig. 4. It is seen that the partition results from the three approaches are largely the same as their counterparts in the UD specimen. That is, the addition of the $\pm 15^{\circ}$ angle plies, sandwiching the two $0^{\circ}$ fracture layers, has negligible effect on the partition; however, the fracture toughness has some changes. Some are significant. For example, the toughness of UD UENF 20/12 in Table 2 is $1259 \mathrm{~N} / \mathrm{m}$ while the toughness of CUD UENF 20/12 in Table 3 is 976 N/m. Wang and Harvey's Euler beam partition theory and Davidson et al.’s non-singular-field partition theory both agree well with the failure locus, except for the UENF specimen. It is noted that the singular-field partition approach has similar performance to that observed for the UD specimens in Table 2 and Fig. 2.

\subsection{Multidirectional specimens}

MD specimens made from C12K/R6376 material are considered in this sub-section with offset delaminations. The specimen layups are given at the bottom of Table 4 and the partition results are shown in Table 4 and Fig. 5. The partition results from singular-field partition approach are 
still in poor agreement with the failure locus. The partition results from Wang and Harvey's Euler beam partition theory and Davidson et al.'s non-singular-field partition theory have significant differences. Although they are both still in a better agreement with the failure locus than the singular field approach, the agreement is not as good as that seen for the UD and CUD specimens.

Two test configurations in particular are far from the failure locus: (1) for the USLB 12/24 specimen with layup F, the partitions obtained from both partition theories are far beyond one standard deviation away from the mean value. (2) For the USLB 24/12 specimen with layup F, the partition result from Davidson et al.’s non-singular-field partition theory is also far beyond one standard deviation away. The following three possible causes are explored:

(1) Errors in the experiments. The experimental work in Refs. [6,7] is some of the most comprehensive and thorough reported in literature so far, and as stated in these references, the aim was to obtain the most accurate results. Each test was repeated at least five times. From Table 4, it is seen that one standard deviation of the fracture toughness is only about $6 \%$ of the total fracture toughness for both specimens; therefore, significant errors in the experiments can be discounted.

(2) Effect of layup on the accuracy of the partition theory-Does either of the partition theories work correctly for MD layups? To show the effect of the layup on each partition theory, the partition results for offset delamination in all the specimens in Tables 2, 3 and 4 for the loading case $M_{2} / M_{1}=0$ are collected together in Table 5 . Note that the results in the brackets are from Table 6 for the second set of MD specimens in Ref. [7] as well as the two USLB UD specimens in this same reference, made from T800H/3900-2 graphite/epoxy. These will be discussed shortly. Specimens of different layups are grouped according to the thickness ratio $\gamma$. It is seen that the partition results from Wang and Harvey's Euler beam partition theory are almost independent of layup and material properties, and only depends on the thickness ratio $\gamma$. The 
partition results from Davidson et al.’s non-singular-field partition theory and the singular-field approach are both insensitive to material properties; however, they both depend on the layup and the thickness ratio $\gamma$. It is more important however to note that each group of specimens made from the same material have similar fracture toughness except for the 12/24 USLB specimen with layup F, which is made from C12K/R6376 material. This observation strongly suggests that Wang and Harvey's Euler beam partition theory provides the correct partition and is more accurate than the other two approaches. In order to confirm this suggestion the third possible cause needs to be explored.

(3) Effect of the different fracture toughness values, $G_{I c}$ and $G_{\text {IIc }}$, between two different crack interfaces, for example, $0 / 0$ vs. $0 / 45$. It is obvious that if the fracture toughness values $G_{I c}$ and $G_{\text {IIc }}$ of the angle ply interfaces in the MD specimens are different from that of the UD specimens, even the correct partition results for MD specimens will not agree well with the failure locus determined from the midplane UD specimens.

In order to purely assess the accuracy of partition theories without influence of the third possible cause, the second set of MD specimens [7] which are made from T800H/3900-2 graphite epoxy material is considered. Since the material has high toughness, it is expected that an angle ply interface and a UD ply interface should have approximately the same fracture toughness values, $G_{\text {IC }}$ and $G_{\text {IIc }}$. It is then reasonable to assume that the two interfaces have the same failure locus. Therefore, the correct partition should produce the same failure locus. Thus the effect of the difference between the fracture toughness values $G_{I c}$ and $G_{I I c}$ from two different interfaces can be eliminated. The second set of MD specimens [7] have the same layups as those from the first set in Table 4. The partition results are given in Table 6 and Fig. 6. The straight line in Fig. 6 is the failure locus obtained from UD midplane delamination tests. As the test results fall almost exactly on the line, they are not plotted on the figure for clarity. It is impressive to see that partition results from Wang and Harvey's Euler beam partition theory for the MD specimens 
fall almost exactly on the line except for the 24/12 USLB specimen with layup E. This test however has a large standard deviation for its fracture toughness measurements. Reference [7] says that there may have been some errors in the testing of this specimen. Overall, this data for the second set of MD specimens [7] clearly shows that Wang and Harvey's Euler beam partition theory is likely to be the most accurate one. It is also noted that both Davidson et al.'s nonsingular-field partition theory [4-6] and the singular field approach have better agreement with the failure locus than they do for the first set of MD specimens in Table 4 and Fig. 5.

We therefore conclude that the relatively poor performance of the three approaches for the first set of MD specimens with low toughness is due to difference between the fracture toughness values, $G_{I c}$ and $G_{I I c}$, for angle ply and UD ply interfaces. To explore this point further, Fig. 2 is redrawn in the form of $G_{I}$ vs. $G_{I I}$ in Fig. 7. It is seen that a linear failure locus is a good approximation for the midplane delamination of UD specimens. The linear failure loci for offset delamination from both Wang and Harvey's Euler beam partition theory and Davidson et al.'s non-singular-field partition theory are also plotted. The former almost exactly coincides with the midplane failure locus and the latter agrees very well. Based on this observation, it is assumed that the angle ply interfaces in the MD specimens in Table 4 and Fig. 5 also have linear failure locus. It is shown in Fig. 7 for the MD specimens with layup F (the layup with the worst agreement), that the value of $G_{I c}$ is over $400 \mathrm{~N} / \mathrm{m}$, which is considerably larger than that of the UD one. This further supports the conclusion above.

\section{Conclusions}

By using some of the most comprehensive and thorough experimental test data to be found in the literature [6,7], three approaches to partitioning a mixed mode are assessed. They are: (1) Wang and Harvey’s Euler beam partition theory [8-11]; (2) Davidson et al.’s non-singular-field partition theory [4-6]; and (3) finite element simulation based on 2D elasticity to obtain the 
singular-field partition. Wang and Harvey's Euler beam partition theory [8-11] is derived completely analytically while Davidson et al.'s non-singular-field partition theory [4-6] is derived with the aid of experimental test results.

Wang and Harvey's Euler beam partition theory [8-11] has excellent agreement with experimental test results and gives very accurate predictions of interfacial fracture toughness laminated composite beams with arbitrary layups, various thickness ratios and various loading conditions. It is a very valuable theory for academic research of fracture and fatigue of advanced materials. Furthermore, it can play a very valuable role in the design of engineering structures made of layered materials.

Davidson et al.'s non-singular-field partition theory [4-6] has excellent agreement with experimental test results and with Wang and Harvey's Euler beam partition theory [8-11] (inside the range $1 / 3<\gamma<3$ ) for UD laminated composite materials. Its accuracy is still very good for MD laminated composite beams; however, it has been observed and argued that overall Wang and Harvey's Euler beam partition theory [8-11] offers improved accuracy. In general, the singular-field approach based on 2D elasticity and the finite element method give poor predictions.

Finally, it is worth noting that different fracture toughness values, $G_{I c}$ and $G_{I I c}$, for angle ply and UD ply interfaces results in different failure loci. Therefore care has to be taken when making comparisons between the two in order to compare like with like.

\section{Acknowledgements}

The authors are very grateful to Professor Barry Davidson of Syracuse University NY for checking some of their calculations that use his crack tip element non-singular-field partition theory. 


\section{Appendix A. The coefficient matrix $[C]$ of the ERR G in Eq. (1)}

The symmetric coefficient matrix of quadratic form given in Eq (1) is

$$
[C]=\left[\begin{array}{cccc}
\frac{1}{D_{1}^{*}}-\frac{1}{D^{*}} & -\frac{1}{D^{*}} & \frac{h_{2}}{2 D^{*}}-\frac{B_{1}}{B_{1}^{*}}+\frac{B}{B^{*}} & \frac{B}{B^{*}}-\frac{h_{1}}{2 D^{*}} \\
\cdots & \frac{1}{D_{2}^{*}}-\frac{1}{D^{*}} & \frac{h_{2}}{2 D^{*}}+\frac{B}{B^{*}} & \frac{B}{B^{*}}-\frac{B_{2}}{B_{2}^{*}}-\frac{h_{1}}{2 D^{*}} \\
\cdots & \cdots & \frac{1}{A_{1}^{*}}-\frac{B h_{2}}{B^{*}}-\frac{1}{A^{*}}-\frac{h_{2}^{2}}{4 D^{*}} & \frac{B\left(h_{1}-h_{2}\right)}{2 B^{*}}-\frac{1}{A^{*}}+\frac{h_{1} h_{2}}{4 D^{*}} \\
\cdots & \cdots & \ldots & \frac{B h_{1}}{B^{*}}+\frac{1}{A_{2}^{*}}-\frac{1}{A^{*}}-\frac{h_{1}^{2}}{4 D^{*}}
\end{array}\right]
$$

where symmetrical terms are denoted by '...'

Appendix B. The details of $c_{I E}, c_{I I E},\left(\theta_{i}, \beta_{i}\right)$ and $\left(\theta_{i}^{\prime}, \beta_{i}^{\prime}\right)(i=1,2,3)$ in Eqs. (4) and (5)

$$
\begin{gathered}
\theta_{1}=\frac{\left(B_{2}^{2}-A_{2} D_{2}\right)\left(B_{1}+h_{1} A_{1} / 2\right)}{\left(B_{1}^{2}-A_{1} D_{1}\right)\left(B_{2}-h_{2} A_{2} / 2\right)} \\
\theta_{2}=-\frac{B_{1}+h_{1} A_{1} / 2}{D_{1}+h_{1} B_{1} / 2} \\
\theta_{3}=\frac{\left(B_{1}+h_{1} A_{1} / 2\right)\left(B_{2}^{2}-A_{2} D_{2}\right)}{\left(D_{2}-h_{2} B_{2} / 2\right)\left(B_{1}^{2}-A_{1} D_{1}\right)} \\
\beta_{2}=\frac{D_{2}^{*}\left(D_{1}^{*}+D_{1}^{*} \theta_{1}-D^{*}\right)}{D_{1}^{*}\left(D_{2}^{*}+D_{2}^{*} \theta_{1}-D^{*} \theta_{1}\right)} \\
\left.\theta_{2}\left(\frac{B h_{2}}{B^{*}}-\frac{1}{\theta_{1}^{*}}+\frac{1}{A^{*}}+\frac{B_{1}}{B_{1}^{*}}+\frac{B}{B^{*}}\right)+\frac{1}{D_{1}^{*}}-\frac{1}{D^{*}}\right)-\frac{h_{2}}{2 D^{*}}+\frac{B_{1}}{B_{1}^{*}}-\frac{B}{B^{*}} \\
\beta_{3}=\frac{\theta_{3}\left(\frac{h_{1}}{2 D^{*}}-\frac{B}{B^{*}}\right)-\frac{1}{D_{1}^{*}}+\frac{1}{D^{*}}}{\theta_{3}\left(\frac{B h_{1}}{B^{*}}+\frac{1}{A_{2}^{*}}-\frac{1}{A^{*}}-\frac{h_{1}^{2}}{4 D^{*}}\right)-\frac{h_{1}}{2 D^{*}}+\frac{B}{B^{*}}}
\end{gathered}
$$




$$
\begin{aligned}
& \theta_{2}^{\prime}=\frac{\beta_{2}^{\prime}\left(\frac{h_{2}}{2 D^{*}}-\frac{B_{1}}{B_{1}^{*}}+\frac{B}{B^{*}}\right)+\frac{1}{D_{1}^{*}}-\frac{1}{D^{*}}}{\beta_{2}^{\prime}\left(\frac{B h_{2}}{B^{*}}-\frac{1}{A_{1}^{*}}+\frac{1}{A^{*}}+\frac{h_{2}^{2}}{4 D^{*}}\right)-\frac{h_{2}}{2 D^{*}}+\frac{B_{1}}{B_{1}^{*}}-\frac{B}{B^{*}}} \\
& \theta_{3}^{\prime}=\frac{\beta_{3}^{\prime}\left(\frac{h_{1}}{2 D^{*}}-\frac{B}{B^{*}}\right)-\frac{1}{D_{1}^{*}}+\frac{1}{D^{*}}}{\beta_{3}^{\prime}\left(\frac{B h_{1}}{B^{*}}+\frac{1}{A_{2}^{*}}-\frac{1}{A^{*}}-\frac{h_{1}^{2}}{4 D^{*}}\right)-\frac{h_{1}}{2 D^{*}}+\frac{B}{B^{*}}} \\
& \beta_{1}^{\prime}=\frac{D_{2}^{*}}{D_{1}^{*}} \\
& \beta_{2}^{\prime}=-\frac{A_{1}}{B_{1}} \\
& \beta_{3}^{\prime}=-\frac{B_{2}^{*}}{D_{1}^{*} B_{2}} \\
& c_{I E}=G_{\theta_{1}}\left[\left(1-\frac{\theta_{1}}{\beta_{1}}\right)\left(1-\frac{\theta_{1}}{\beta_{1}^{\prime}}\right)\right]^{-1} \\
& c_{I I E}=G_{\beta_{1}}\left[\left(1-\frac{\beta_{1}}{\theta_{1}}\right)\left(1-\frac{\beta_{1}}{\theta_{1}^{\prime}}\right)\right]^{-1} \\
& G_{\theta_{1}}=\frac{1}{2 b^{2}}\left[\frac{1}{D_{1}^{*}}+\frac{\theta_{1}^{2}}{D_{2}^{*}}-\frac{\left(1+\theta_{1}\right)^{2}}{D^{*}}\right] \\
& G_{\beta_{1}}=\frac{1}{2 b^{2}}\left[\frac{1}{D_{1}^{*}}+\frac{\beta_{1}^{2}}{D_{2}^{*}}-\frac{\left(1+\beta_{1}\right)^{2}}{D^{*}}\right]
\end{aligned}
$$

Appendix C. The details of $c_{I E}, c_{I I E},\left(\theta_{i}, \beta_{i}\right)$ and $\left(\theta_{i}^{\prime}, \beta_{i}^{\prime}\right)$ in Eqs. (7) and (8)

$$
\begin{gathered}
\theta_{1}=-\gamma^{2} \\
\theta_{2}=-\frac{6}{h_{1}} \\
\beta_{1}=\frac{\gamma^{2}(3+\gamma)}{1+3 \gamma} \\
\beta_{2}=\frac{2(3+\gamma)}{h_{1}(\gamma-1)} \text { for } \gamma \neq 1 \\
=1 \text { for } \gamma=1 \\
\theta_{1}^{\prime}=-1
\end{gathered}
$$




$$
\begin{gathered}
\theta_{2}^{\prime}=-\frac{6(1+\gamma)}{h_{1}\left(1+\gamma^{3}\right)} \\
\beta_{1}^{\prime}=\gamma^{3} \\
c_{I E}=G_{\theta_{1}}\left[\left(1-\frac{\theta_{1}}{\beta_{1}}\right)\left(1-\frac{\theta_{1}}{\beta_{1}^{\prime}}\right)\right]^{-1} \\
C_{I I E}=G_{\beta_{1}}\left[\left(1-\frac{\beta_{1}}{\theta_{1}}\right)\left(1-\frac{\beta_{1}}{\theta_{1}^{\prime}}\right)\right]^{-1} \\
G_{\theta_{1}}=\frac{24 \gamma}{E b^{2} h_{1}^{3}(1+\gamma)} \\
G_{\beta_{1}}=\frac{72 \gamma(1+\gamma)}{b^{2} E h_{1}^{3}(1+3 \gamma)^{2}}
\end{gathered}
$$




\section{References}

1. Williams JG. On the calculation of energy release rates for cracked laminates. Int J Fract Mech 1988;36:101-19.

2. Suo Z, Hutchinson JW. Interface crack between two elastic layers. Int J Fract 1990;43:1-18.

3. Hutchinson JW, Suo Z. Mixed mode cracking in layered materials. Adv Appl Mech 1992;29:63-191.

4. Davidson BD, Hu H, Schapery RA. An analytical crack tip element for layered elastic structures. J Appl Mech-T ASME 1995;62:294-305.

5. Davidson BD, Peter L, Fariello PL, Hudson RC, Sundararaman V. Accuracy assessment of the singular field-based mode mix decomposition procedure for the prediction of delamination. Composite Materials: Testing and Design (Thirteenth Volume), ASTM STP 1242, SJ Hooper, Ed., American Society for Testing and Materials, 1997, pp. 109-28.

6. Davidson BD, Gharibian SJ, Yu L. Evaluation of energy release rate-based approaches for predicting delamination growth in laminated composites. Int J Fract Mech 2000;105:343-65.

7. Davidson BD, Bialaszewski RD, Sainath SS. A non-classical, energy release rate based approach for predicting delamination growth in graphite reinforced laminated polymeric composites. Compos Sci Tech 2006;66:1479-1496.

8. Wang S, Harvey C. A theory of one-dimensional fracture. Compos Struct 2012;94:758-67. Also a plenary lecture at the $16^{\text {th }}$ International Conference on Composite Structures (ICCS16), 28-30 ${ }^{\text {th }}$ June 2011, Porto, Portugal.

9. Wang S, Harvey C. Mixed mode partition theories for one dimensional fracture. Eng Fract Mech 2012;79:329-52.

10. Harvey C, Wang S. Mixed-mode partition theories for one-dimensional delamination in laminated composite beams. Eng Fract Mech 2012;96:737-59. 
11. Harvey CM, Wang S. Experimental assessment of mixed-mode partition theories. Compos Struct 2012;94:2057-67.

12. Harvey CM, Wood JD, Wang S, Watson A. A novel method for the partition of mixed-mode fractures in 2D elastic laminated unidirectional composite beams. Compos Struct 2014;116:589-94.

13. Hashemi S, Kinloch AJ, Williams JG. The analysis of interlaminar fracture in uniaxial fibrepolymer composites. Proc R Soc Lond A 1990;427:173-99.

14. Kinloch AJ, Wang Y, Williams JG, Yayla P. The mixed-mode delamination of fibre composite materials. Compos Sci Technol 1993;47:225-37.

15. Charalambides M, Kinloch AJ, Wang W, Williams JG. On the analysis of mixed-mode failure. Int J Fract 1992;54:269-91.

16. Hashemi S, Kinloch AJ, Williams G. Mixed-mode fracture in fiber-polymer composite laminates. In: O’Brien TK, editor. Composite materials: fatigue and fracture (third volume), ASTM STP 1110. Philadelphia, PA: American Society for Testing and Materials, 1991. p. 143-68.

17. Conroy M, Sørensen BF, Ivankovic A. Combined numerical and experimental investigation of mode-mixity in beam like geometries. In: Proceedings of the 37th annual meeting of the Adhesion Society, San Diego CA, Feburary 2014.

18. Wang S, Harvey CM, Guan L. Partition of mixed modes in layered isotropic double cantilever beams with non-rigid cohesive interfaces. Eng Fract Mech 2013;111:1-25. 


\section{Figure captions}

Fig. 1: A double cantilever beam. (a) General description. (b) Crack tip forces.

Fig. 2: Fracture toughness of midplane and offset delaminations in unidirectional laminates made from C12K/R6376 [6].

Fig. 3: Difference between $G_{I I} / G$ from Wang and Harvey’s Euler beam partition theory [8-11] and Davidson et al.’s partition theory [4-6] with overlaid test points for unidirectional beams [6].

Fig. 4: Fracture toughness of midplane and offset delaminations in constrained unidirectional laminates made from C12K/R6376 [6].

Fig. 5: Fracture toughness of midplane and offset delaminations in multidirectional laminates made from C12K/R6376 [6].

Fig. 6: Fracture toughness of midplane and offset delaminations in multidirectional laminates T800H/3900-2 [7].

Fig. 7: Mixed-mode failure loci for laminates made from C12K/R6376 with a unidirectional layup and with multidirectional layup F [6]. 


\section{Table captions}

Table 1: Unidirectional material properties [6,7].

Table 2: Fracture toughness of midplane and offset delaminations in unidirectional laminates made from C12K/R6376 [6].

Table 3: Fracture toughness of midplane and offset delaminations in constrained unidirectional laminates made from C12K/R6376 [6].

Table 4: Fracture toughness of midplane and offset delaminations in multidirectional laminates made from C12K/R6376 [6].

Table 5: Fracture toughness of offset delaminations under the loading case $M_{2} / M_{1}=0[6,7]$.

Table 6: Fracture toughness of midplane and offset delaminations in multidirectional laminates T800H/3900-2 [7]. 


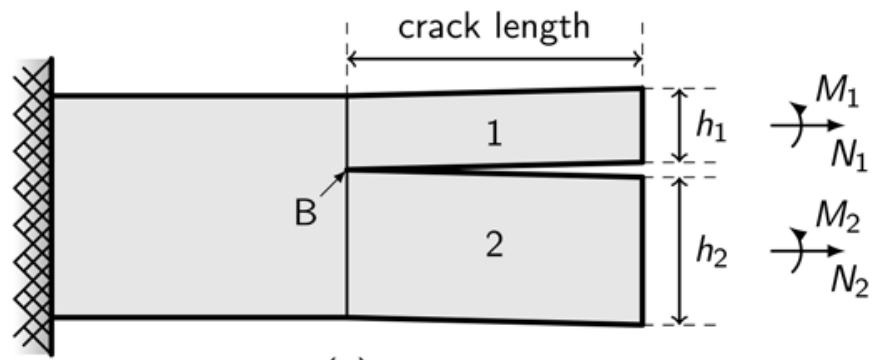

(a)

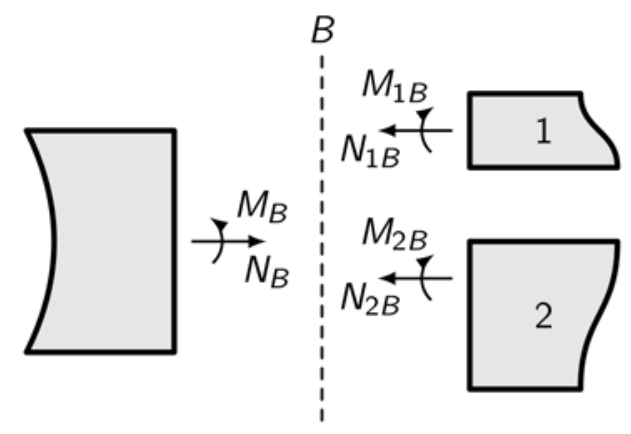

(b)

Fig. 1: A double cantilever beam. (a) General description. (b) Crack tip forces. 


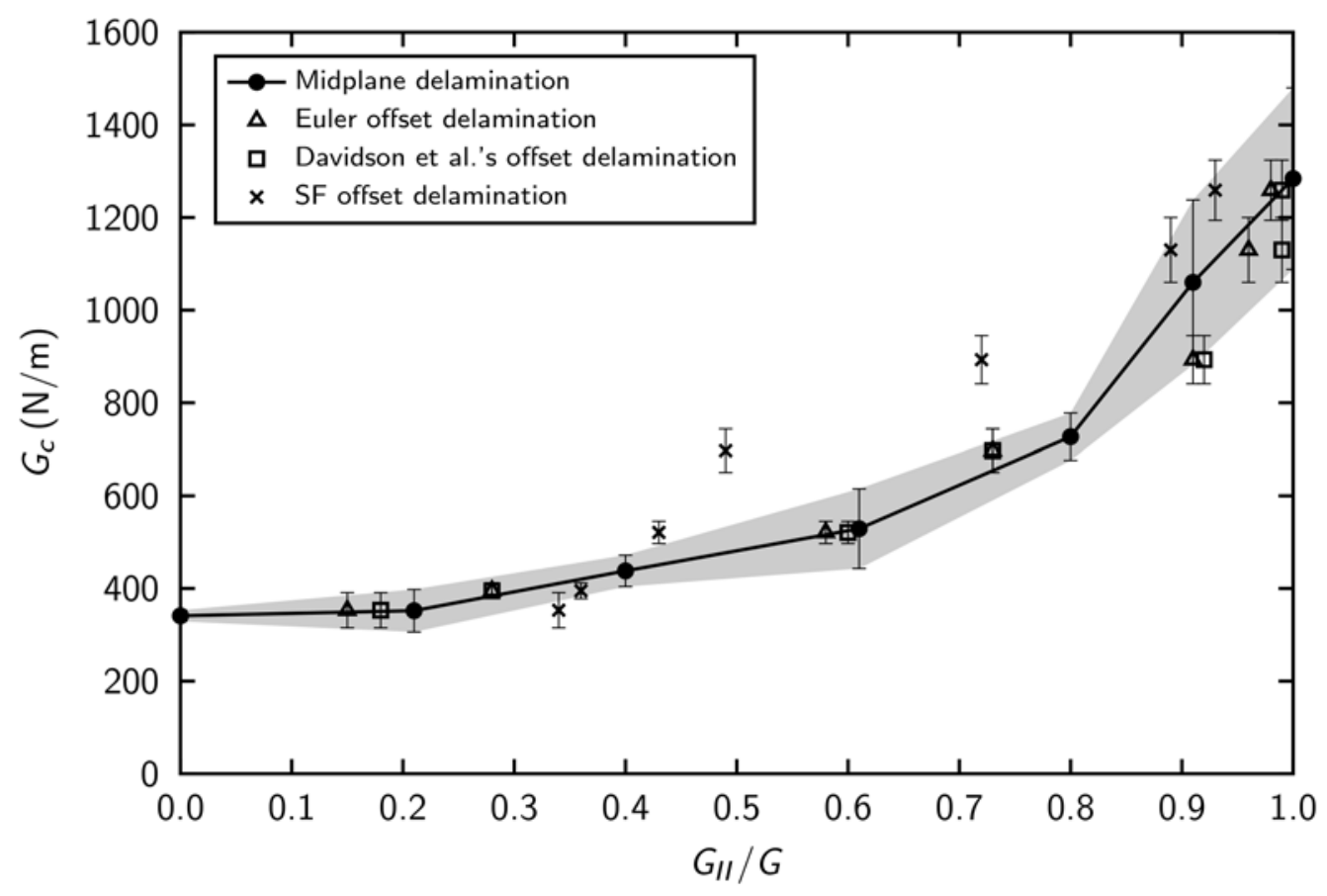

Fig. 2: Fracture toughness of midplane and offset delaminations in unidirectional laminates made from C12K/R6376 [6]. 


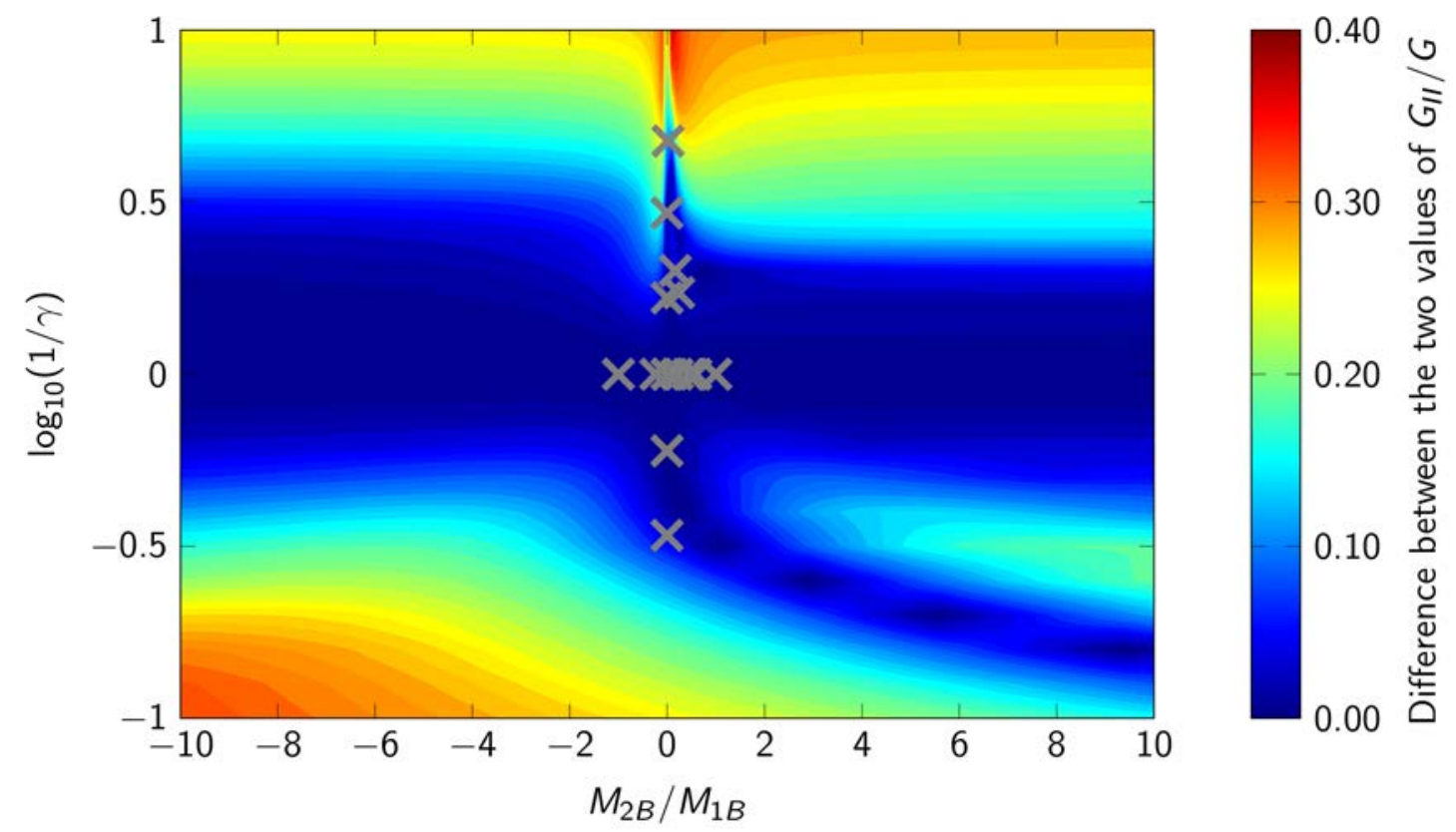

Fig. 3: Difference between $G_{I I} / G$ from Wang and Harvey’s Euler beam partition theory [8-11] and Davidson et al.'s partition theory [4-6] with overlaid test points for unidirectional beams [6]. 


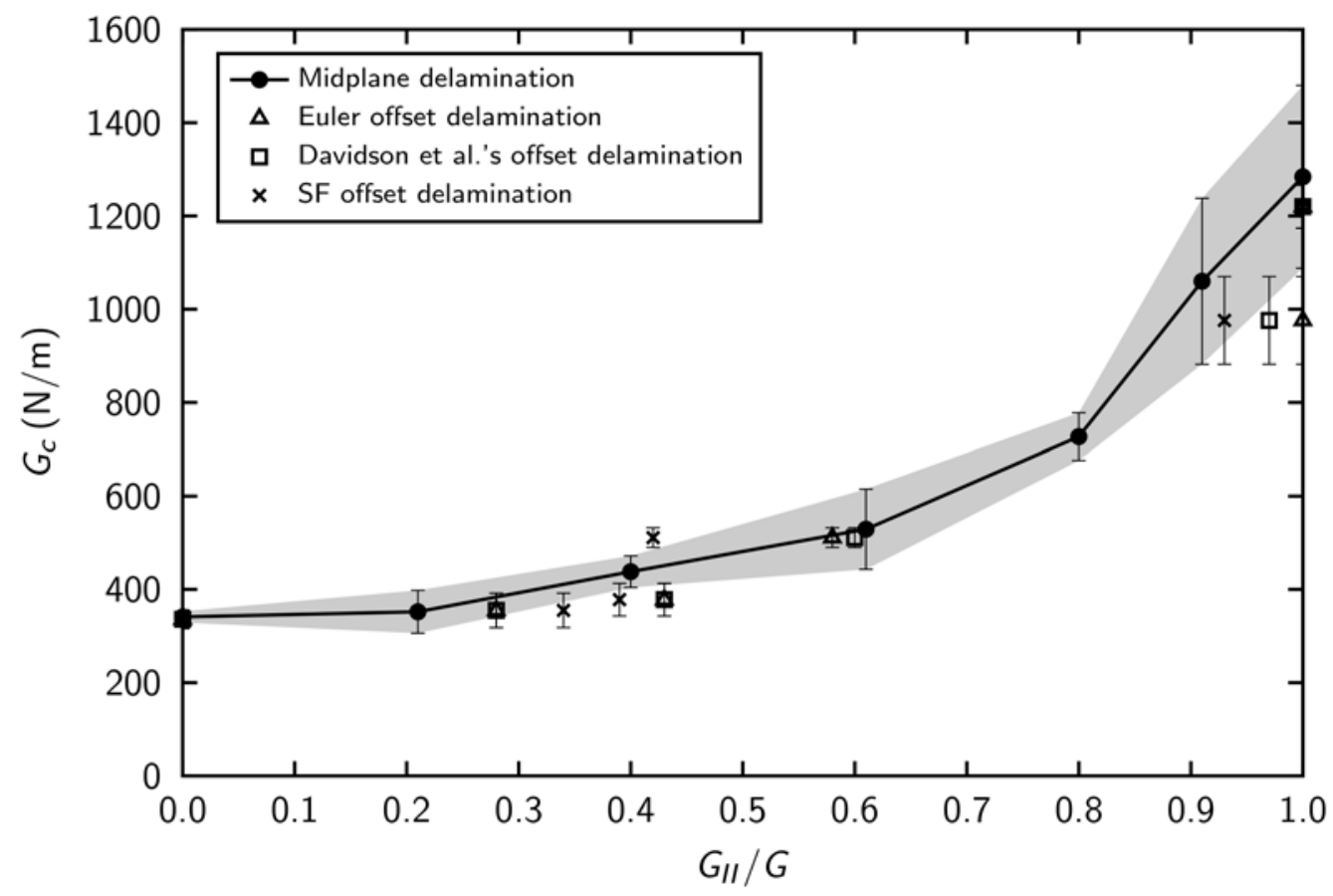

Fig. 4: Fracture toughness of midplane and offset delaminations in constrained unidirectional laminates made from C12K/R6376 [6]. 


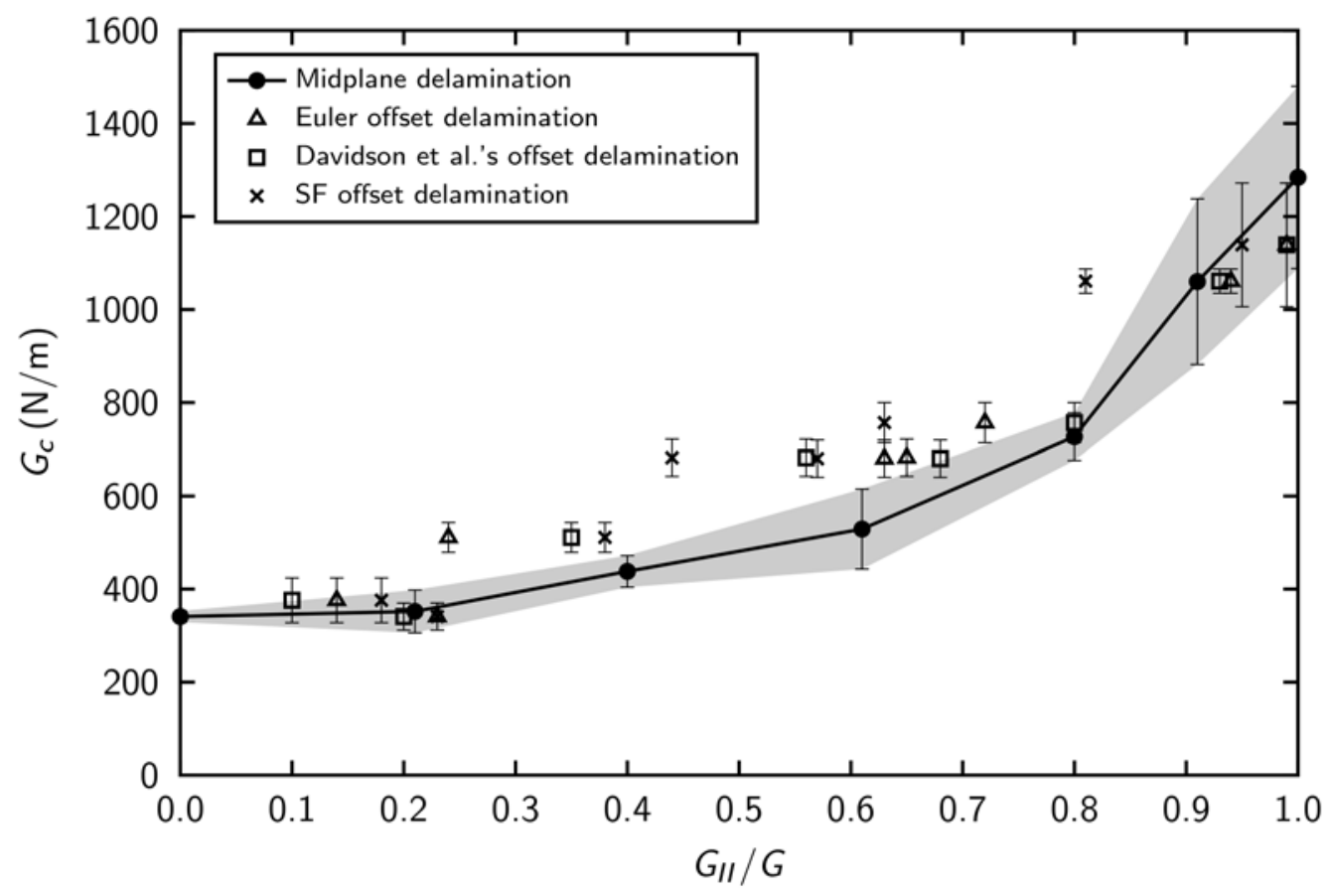

Fig. 5: Fracture toughness of midplane and offset delaminations in multidirectional laminates made from C12K/R6376 [6]. 


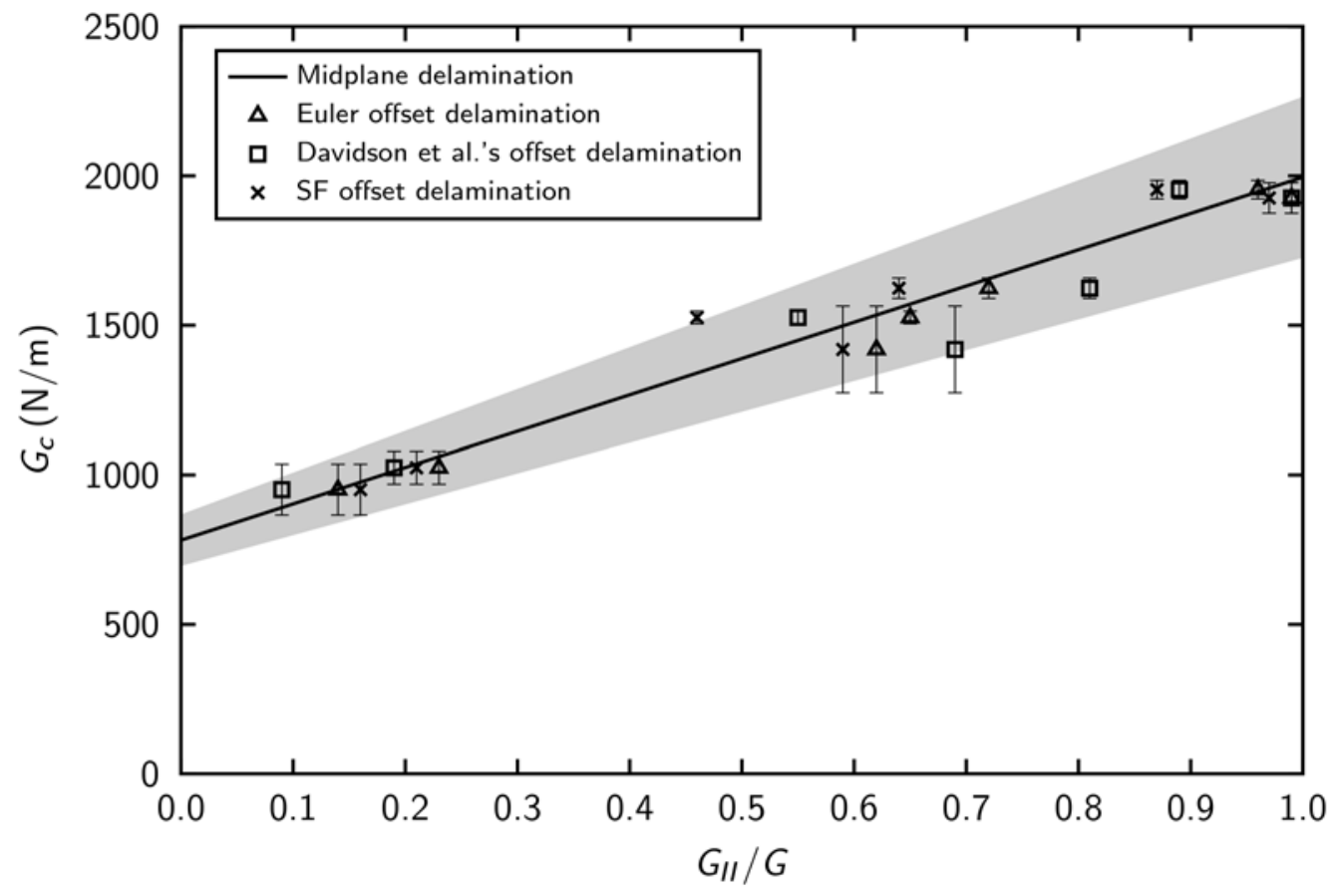

Fig. 6: Fracture toughness of midplane and offset delaminations in multidirectional laminates T800H/3900-2 [7]. 


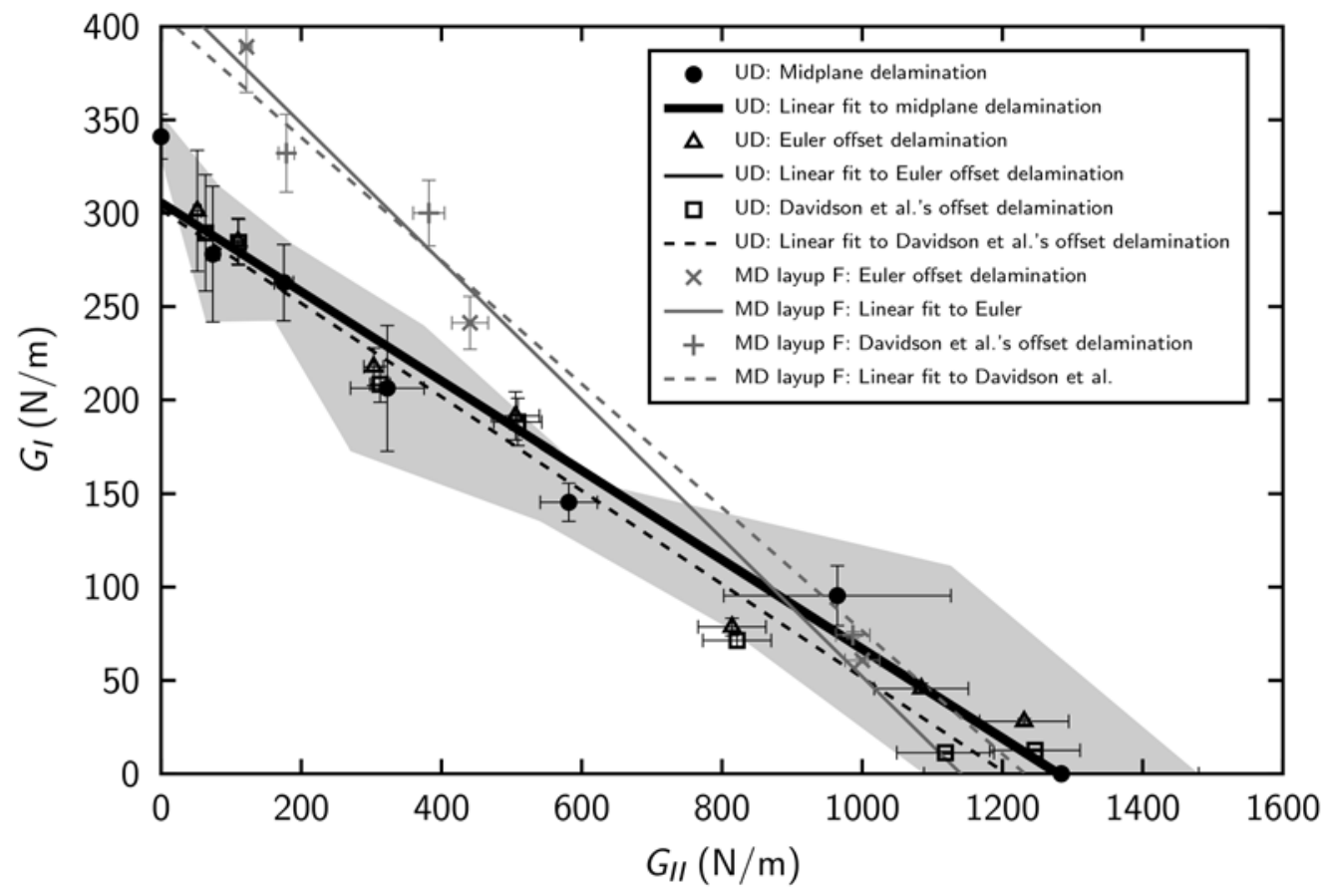

Fig. 7: Mixed-mode failure loci for laminates made from C12K/R6376 with a unidirectional layup and with multidirectional layup F [6]. 
Table 1: Unidirectional material properties [6,7].

\begin{tabular}{ccc}
\hline & C12K/R6376 graphite/epoxy & T800H/3900-2 graphite/epoxy \\
\hline$E_{11}(\mathrm{GPa})$ & 146.86 & 154.72 \\
$E_{22}, E_{33}(\mathrm{GPa})$ & 10.62 & 7.58 \\
$\mu_{12}, \mu_{13}(\mathrm{GPa})$ & 5.45 & 4.27 \\
$\mu_{23}(\mathrm{GPa})$ & 3.99 & 2.88 \\
$v_{12}, v_{13}, v_{23}$ & 0.33 & 0.32 \\
$E_{1 \mathrm{f}}(\mathrm{GPa})$ & 114.15 & 143.13 \\
\hline
\end{tabular}


Table 2: Fracture toughness of midplane and offset delaminations in unidirectional laminates made from C12K/R6376 [6].

\begin{tabular}{ccccccccc}
\hline & & & & \multicolumn{3}{c}{ Calculated partition, $G_{I I} / G$} & & \\
\cline { 5 - 6 } Test & $n_{1} / n_{2}$ & $\gamma=h_{2} / h_{1} * *$ & $M_{2} / M_{1}$ & SF [6] & $\begin{array}{c}\text { Davidson et } \\
\text { al. [6] }\end{array}$ & Euler & $G_{c}(\mathrm{~N} / \mathrm{m})$ & $\begin{array}{c} \pm \sigma(\mathrm{N} / \mathrm{m}) \\
\text { error }\end{array}$ \\
\cline { 1 - 3 } DCB & $16 / 16$ & 1.00 & -1.00 & 0.00 & 0.00 & 0.00 & 341 & 12 \\
SSLB & $16 / 16$ & 1.00 & 0.00 & 0.40 & 0.43 & 0.43 & 438 & 34 \\
ENF & $16 / 16$ & 1.00 & 1.00 & 1.00 & 1.00 & 1.00 & 1284 & 196 \\
MMB* & $12 / 12$ & 1.00 & -0.23 & 0.21 & 0.23 & 0.23 & 352 & 46 \\
MMB* & $12 / 12$ & 1.00 & 0.01 & 0.40 & 0.44 & 0.44 & 438 & 34 \\
MMB* & $12 / 12$ & 1.00 & 0.21 & 0.61 & 0.64 & 0.64 & 529 & 86 \\
MMB* & $12 / 12$ & 1.00 & 0.44 & 0.80 & 0.83 & 0.83 & 727 & 51 \\
MMB* & $12 / 12$ & 1.00 & 0.59 & 0.91 & 0.92 & 0.92 & 1060 & 178 \\
MMB* & $12 / 12$ & 1.00 & 1.00 & 1.00 & 1.00 & 1.00 & 1284 & 196 \\
USLB & $8 / 24$ & 2.94 & 0.00 & 0.34 & 0.18 & 0.15 & 353 & 38 \\
USLB & $12 / 20$ & 1.67 & 0.00 & 0.36 & 0.28 & 0.28 & 395 & 17 \\
USLB & $20 / 12$ & 0.60 & 0.00 & 0.43 & 0.60 & 0.58 & 521 & 24 \\
USLB & $24 / 8$ & 0.34 & 0.00 & 0.49 & 0.73 & 0.73 & 697 & 47 \\
UENF & $25 / 5$ & 0.21 & $0.02(0.004)$ & 0.72 & 0.92 & 0.91 & 893 & 52 \\
UENF & $20 / 10$ & 0.50 & $0.17(0.10)$ & 0.89 & 0.99 & 0.96 & 1130 & 70 \\
UENF & $20 / 12$ & 0.58 & $0.24(0.18)$ & 0.93 & 0.99 & 0.98 & 1259 & 65 \\
\hline
\end{tabular}

* 24-ply UD MMB laminates, ply thickness $t_{p}=0.155 \mathrm{~mm}$ (for all other UD laminates, ply thickness $t_{p}=0.146 \mathrm{~mm}$ )

** These thickness ratios refer to the actual average thickness ratio as measured from the test specimens [6] 
Table 3: Fracture toughness of midplane and offset delaminations in constrained unidirectional laminates made from C12K/R6376 [6].

\begin{tabular}{ccccccccccc}
\hline & & & & \multicolumn{5}{c}{ Calculated partition, $G_{I I} / G$} & \\
\cline { 6 - 8 } Test & $n_{1} / n_{2}$ & $\gamma=h_{2} / h_{1}$ & $\begin{array}{c}\text { Stacking } \\
\text { sequence }\end{array}$ & $M_{2} / M_{1}$ & SF [6] & $\begin{array}{c}\text { Davidson } \\
\text { et al. [6] }\end{array}$ & Euler & $G_{c}(\mathrm{~N} / \mathrm{m})$ & $\begin{array}{c} \pm \sigma(\mathrm{N} / \mathrm{m}) \\
\text { error }\end{array}$ \\
\hline DCB & $16 / 16$ & 1.00 & $\mathrm{~A}$ & -1.00 & 0.00 & 0.00 & 0.00 & 336 & 20 \\
SSLB & $16 / 16$ & 1.00 & $\mathrm{~A}$ & 0.00 & 0.39 & 0.43 & 0.43 & 378 & 35 \\
ENF & $16 / 16$ & 1.00 & $\mathrm{~A}$ & 1.00 & 1.00 & 1.00 & 1.00 & 1220 & 46 \\
USLB & $12 / 20$ & 1.67 & $\mathrm{~B}$ & 0.00 & 0.34 & 0.28 & 0.28 & 355 & 37 \\
USLB & $20 / 12$ & 0.60 & $\mathrm{C}$ & 0.00 & 0.42 & 0.60 & 0.58 & 511 & 21 \\
UENF & $20 / 12$ & 0.60 & $\mathrm{C}$ & $0.22(0.22)$ & 0.93 & 0.97 & 1.00 & 976 & 94 \\
\hline
\end{tabular}

Stacking sequence (ply thickness $t_{p}=0.159 \mathrm{~mm}$ ):
A : $\left[0 / 10 /-15 / 0_{10} /-15 / 10 / 0 / d\right]_{S}$
B : $\left[(0 / \pm 15 / 0)_{3} / \mathrm{d} /(0 / \mp 15 / 0) /(0 / \mp 15 / 0)_{4}\right]$
C : $\left[(0 / \pm 15 / 0)_{4} / \mathrm{d} /(0 / \mp 15 / 0) /(0 / \mp 15 / 0)_{3}\right]$ 
Table 4: Fracture toughness of midplane and offset delaminations in multidirectional laminates made from C12K/R6376 [6].

\begin{tabular}{|c|c|c|c|c|c|c|c|c|c|}
\hline \multirow[b]{2}{*}{ Test } & \multirow[b]{2}{*}{$n_{1} / n_{2}$} & \multirow[b]{2}{*}{$\gamma=h_{2} / h_{1}$} & \multirow[b]{2}{*}{$\begin{array}{l}\text { Stacking } \\
\text { sequence }\end{array}$} & \multirow[b]{2}{*}{$M_{2} / M_{1}$} & \multicolumn{3}{|c|}{ Calculated partition, $G_{I I} / G$} & \multirow[b]{2}{*}{$G_{c}(\mathrm{~N} / \mathrm{m})$} & \multirow[b]{2}{*}{$\begin{array}{c} \pm \sigma(\mathrm{N} / \mathrm{m}) \\
\text { error }\end{array}$} \\
\hline & & & & & SF [6] & $\begin{array}{l}\text { Davidson } \\
\text { et al. [6] }\end{array}$ & Euler & & \\
\hline USLB & $8 / 24$ & 3.00 & $\mathrm{D}$ & 0.00 & 0.18 & 0.10 & 0.14 & 376 & 48 \\
\hline USLB & $24 / 8$ & 0.33 & $\mathrm{D}$ & 0.00 & 0.63 & 0.80 & 0.72 & 757 & 43 \\
\hline USLB & $12 / 24$ & 2.00 & E & 0.00 & 0.23 & 0.20 & 0.23 & 341 & 29 \\
\hline USLB & $24 / 12$ & 0.50 & E & 0.00 & 0.57 & 0.68 & 0.63 & 680 & 40 \\
\hline UENF & $24 / 12$ & 0.50 & E & $0.17(0.14)$ & 0.95 & 0.99 & 0.99 & 1139 & 133 \\
\hline USLB & $12 / 24$ & 2.00 & F & 0.00 & 0.38 & 0.35 & 0.24 & 511 & 32 \\
\hline USLB & $24 / 12$ & 0.50 & $\mathrm{~F}$ & 0.00 & 0.44 & 0.56 & 0.65 & 682 & 40 \\
\hline UENF & $24 / 12$ & 0.50 & $\mathrm{~F}$ & $0.11(0.06)$ & 0.81 & 0.93 & 0.94 & 1061 & 26 \\
\hline
\end{tabular}

Stacking sequence (ply thickness $t_{p}=0.152 \mathrm{~mm}$ ):

$\mathrm{D}:\left[(0 / \mp 45 / 90)_{\mathrm{s}} / \mathrm{d} /\left(45 / 90 / 0 /-45_{2} / 0 / 90 / 45\right)_{\mathrm{s}} /(0 / \mp 45 / 90)_{\mathrm{s}}\right]$

$\mathrm{E}:\left[\left( \pm 45 / 0_{2} / \mp 45 / \pm 45 / 0_{2} / \mp 45\right)_{\mathrm{s}} / \mathrm{d} /(0 / \pm 45 / \mp 45 / 0)_{\mathrm{s}}\right]$

$\mathrm{F}:\left[\left(\mp 45 / 0_{8} / \pm 45\right)_{\mathrm{s}} / \mathrm{d} /\left( \pm 45 / 0_{8} / \mp 45\right)\right]$ 
Table 5: Fracture toughness of offset delaminations under the loading case $M_{2} / M_{1}=0$ [6,7].

\begin{tabular}{|c|c|c|c|c|c|c|c|c|}
\hline \multirow[b]{2}{*}{ Test } & \multirow[b]{2}{*}{$n_{1} / n_{2}$} & \multirow[b]{2}{*}{$\gamma=h_{2} / h_{1}$} & \multirow[b]{2}{*}{$\begin{array}{l}\text { Stacking } \\
\text { sequence }\end{array}$} & \multicolumn{3}{|c|}{ Calculated partition, $G_{I I} / G$} & \multirow[b]{2}{*}{$\begin{array}{c}G_{c}(\mathrm{~N} / \mathrm{m}) \\
{[6]([7])}\end{array}$} & \multirow[b]{2}{*}{$\begin{array}{c} \pm \sigma(\mathrm{N} / \mathrm{m}) \\
\text { error [6] ([7]) }\end{array}$} \\
\hline & & & & SF [6] ([7]) & $\begin{array}{l}\text { Davidson et } \\
\text { al. [6] ([7]) }\end{array}$ & Euler & & \\
\hline USLB & $8 / 24$ & 3.00 & D & $0.18(0.16)$ & $0.10(0.09)$ & $0.14(0.14)$ & 376 (951) & $48(85)$ \\
\hline USLB & $8 / 24$ & 2.94 & UD & 0.34 & 0.18 & 0.15 & 353 & 38 \\
\hline USLB & $12 / 24$ & 2.00 & E & $0.23(0.21)$ & $0.20(0.19)$ & $0.23(0.23)$ & 341 (1024) & $29(55)$ \\
\hline USLB & $12 / 24$ & 2.00 & $\mathrm{~F}$ & 0.38 & 0.35 & 0.24 & 511 & 32 \\
\hline USLB & $12 / 20$ & 1.67 & UD & 0.36 & 0.28 & 0.28 & 395 & 17 \\
\hline USLB & $12 / 20$ & 1.67 & B & 0.34 & 0.28 & 0.28 & 355 & 37 \\
\hline USLB & 20/12 & 0.60 & UD & 0.43 & 0.60 & 0.58 & 521 & 24 \\
\hline USLB & 20/12 & 0.60 & C & 0.42 & 0.60 & 0.58 & 511 & 21 \\
\hline USLB & $24 / 12$ & 0.50 & $\mathrm{E}$ & $0.57(0.59)$ & $0.68(0.69)$ & $0.63(0.62)$ & 680 (1419) & 40 (145) \\
\hline USLB & $24 / 12$ & 0.50 & $\mathrm{~F}$ & $0.44(0.46)$ & $0.56(0.55)$ & $0.65(0.65)$ & $682(1526)$ & $40(21)$ \\
\hline USLB & $24 / 8$ & 0.34 & UD & $0.49(0.49)$ & $0.73(0.73)$ & $0.73(0.73)$ & 697 (1807) & 47 (91) \\
\hline USLB & $24 / 8$ & 0.33 & D & $0.63(0.64)$ & $0.80(0.81)$ & $0.72(0.72)$ & 757 (1624) & $43(34)$ \\
\hline USLB* & $18 / 6$ & 0.33 & UD & $(0.48)$ & $(0.73)$ & $(0.73)$ & (1682) & (166) \\
\hline
\end{tabular}

* For this specimen only, ply thickness $t_{p}=0.182 \mathrm{~mm}$, otherwise see Tables 2, 3, 4 and 6 . 
Table 6: Fracture toughness of midplane and offset delaminations in multidirectional laminates T800H/3900-2 [7].

\begin{tabular}{|c|c|c|c|c|c|c|c|c|c|}
\hline \multirow[b]{2}{*}{ Test } & \multirow[b]{2}{*}{$n_{1} / n_{2}$} & \multirow[b]{2}{*}{$\gamma=h_{2} / h_{1}$} & \multirow[b]{2}{*}{$\begin{array}{l}\text { Stacking } \\
\text { sequence }\end{array}$} & \multirow[b]{2}{*}{$M_{2} / M_{1}$} & \multicolumn{3}{|c|}{ Calculated partition, $G_{I I} / G$} & \multirow[b]{2}{*}{$G_{c}(\mathrm{~N} / \mathrm{m})$} & \multirow[b]{2}{*}{$\begin{array}{c} \pm \sigma(\mathrm{N} / \mathrm{m}) \\
\text { error }\end{array}$} \\
\hline & & & & & SF [6] & $\begin{array}{l}\text { Davidson } \\
\text { et al. [6] }\end{array}$ & Euler & & \\
\hline USLB & $8 / 24$ & 3.00 & D & 0.00 & 0.16 & 0.09 & 0.14 & 951 & 85 \\
\hline USLB & $12 / 24$ & 2.00 & E & 0.00 & 0.21 & 0.19 & 0.23 & 1024 & 55 \\
\hline USLB & $24 / 12$ & 0.50 & $\mathrm{~F}$ & 0.00 & 0.46 & 0.55 & 0.65 & 1526 & 21 \\
\hline USLB & $24 / 12$ & 0.50 & E & 0.00 & 0.59 & 0.69 & 0.62 & 1419 & 145 \\
\hline USLB & $24 / 8$ & 0.33 & $\mathrm{D}$ & 0.00 & 0.64 & 0.81 & 0.72 & 1624 & 34 \\
\hline UENF & $24 / 12$ & 0.50 & $\mathrm{~F}$ & $0.10(0.07)$ & 0.87 & 0.89 & 0.96 & 1954 & 31 \\
\hline UENF & $24 / 12$ & 0.50 & E & $0.17(0.15)$ & 0.97 & 0.99 & 0.99 & 1926 & 51 \\
\hline
\end{tabular}

Stacking sequence (ply thickness $t_{p}=0.179 \mathrm{~mm}$ ):

$\mathrm{D}:\left[(0 / \mp 45 / 90)_{\mathrm{s}} / \mathrm{d} /\left(45 / 90 / 0 /-45_{2} / 0 / 90 / 45\right)_{\mathrm{s}} /(0 / \mp 45 / 90)_{\mathrm{s}}\right]$

$\mathrm{E}:\left[\left( \pm 45 / 0_{2} / \mp 45 / \pm 45 / 0_{2} / \mp 45\right)_{\mathrm{s}} / \mathrm{d} /(0 / \pm 45 / \mp 45 / 0)_{\mathrm{s}}\right]$

$\mathrm{F}:\left[\left(\mp 45 / 0_{8} / \pm 45\right)_{\mathrm{s}} / \mathrm{d} /\left( \pm 45 / 0_{8} / \mp 45\right)\right]$ 